\title{
Influence of learning and internship satisfaction on students' intentions to stay at their current jobs: survey of students participating in Taiwan's dual education system
}

\author{
Louis Chih-hung Liu* (D)
}

${ }^{*}$ Correspondence: louisliu@thu.edu.tw Department of Public Management and Policy, Tunghai University, Taichung City 40704, Taiwan

\begin{abstract}
We investigated the effectiveness of Taiwan's dual education system, referred to as the dual system of vocational training policy (DSVTP) program. By surveying 722 randomly selected respondents participating in the DSVTP program, we examined the effects of students' satisfaction with their learning and internship in the program on their intentions to stay at their current jobs. We employed structural equation modeling to analyze the associations among factors. Our empirical results revealed positive correlations between learning satisfaction, job involvement, dual system satisfaction, and intentions to stay at the current job. These empirical results also suggested that students participating DSVTP are largely satisfied with this program and would promote them to stay at current job, which in turn helps to alleviate youth unemployment. On the basis of the statistical analysis results, policy implications that could serve as a reference in future reforms of the DSVTP in Taiwan are also discussed.
\end{abstract}

Keywords: Dual education system, Intentions to stay, Common method variance, Structural equation modeling (SEM), Taiwan

\section{Introduction}

Youth unemployment has been a major problem worldwide (Eichhorst 2014). In Taiwan, the unemployment rate among youth groups (aged 15-24 years) is much higher than that among age groups (Fig. 1). This is mainly because the high enrollment rate of Taiwan's higher education institutes has prompted most young people to further their education in such institutes, and the ones who are employed are mainly working in part-time jobs. According to Palmer (2017), a consultant from the International Labor Organization, skill mismatch is prevalent in unemployed youth presently. This is mainly attributed to the large gap between job seekers' professional skills and the needs of enterprises, which primarily stems from the disjointed connection between labor force training, educational background, and the industrial environment for young people in various countries. The weak linkage between Taiwan's current education system and employment market technologies makes it difficult for students to secure a job that

(c) The Author(s), 2021. Open Access This article is licensed under a Creative Commons Attribution 4.0 International License, which permits use, sharing, adaptation, distribution and reproduction in any medium or format, as long as you give appropriate credit to the original author(s) and the source, provide a link to the Creative Commons licence, and indicate if changes were made. The images or other third party material in this article are included in the article's Creative Commons licence, unless indicated otherwise in a credit line to the material. If material is not included in the article's Creative Commons licence and your intended use is not permitted by statutory regulation or exceeds the permitted use, you will need to obtain permission directly from the copyright holder. To view a copy of this licence, visit http:// creativecommons.org/licenses/by/4.0\%. 


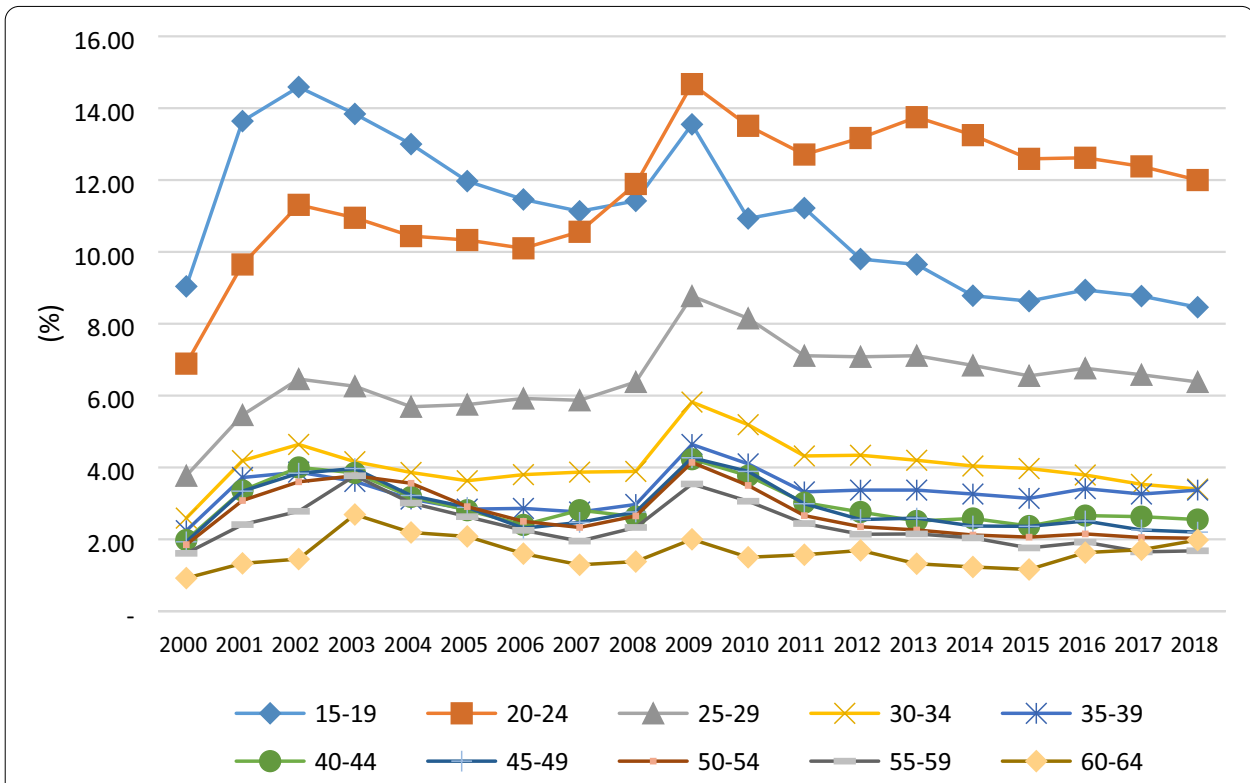

Fig. 1 Unemployment rate in Taiwan by age. Source: Directorate General of Budget, Accounting and Statistics (DGBAS), Executive Yuan (2019). Unemployment Survey Statistics from 2000 to 2018, retrieved on January 10, 2019, from https://www.stat.gov.tw/ct.asp?xltem $=37135 \& c t$ Node $=517 \& \mathrm{mp}=4$

matches their educational background, in turn leading to the so-called education mismatch (Ho 2015). Thus, they end up competing with those with lower educational qualifications, which ultimately leads to a phenomenon in which people with high academic degrees have low job achievement levels (also called over-education).

Numerous studies have highlighted the drawbacks of education mismatch ${ }^{1}$ (Jeong et al. 2018; Kim and Park 2016; Korpi and Tahlin 2009; Nordin et al. 2010; Park 2018; Zhu 2014). Although some studies have mainly focused on the effect of wage disparity, others have primarily focused on the frequent job mobility among people with education mismatch. The limitations engendered by education mismatch warrant attention.

To deal with youth unemployment caused by education mismatch, Taiwan's Ministry of Labor, in cooperation with the Ministry of Education, adopted Germany's dual education system ${ }^{2}$ in 2003, which combines internship in a company and vocational education at a vocational school in one course. This system is practiced in several countries, notably Germany, Switzerland, and Austria (Hanushek 2012). Taiwan's dual education system, which was originally known as the German-Taiwanese Vocational Training Project, promotes youth employment and facilitates the training of high-quality professionals and technical talents who can meet the needs of enterprises.

The dual education system's fundamental scheme is to incorporate the two environments of work and school into the learning process so that students can gain knowledge from schools and enterprises simultaneously. It is organized as collaboration

\footnotetext{
${ }^{1}$ Currently, two types of mismatch exist: vertical mismatch and horizontal mismatch. Vertical education mismatch may refer to either overeducation or undereducation. Horizontal education mismatch simply indicates that an employee's job is unrelated to their major in college.

${ }^{2}$ It is similar to the traditional vocational education and training or dual vocational training.
} 
among training company, schools and industries courses (Forster-Heinzer et al. 2016). Students are expected to attend classes at schools for 2 to 3 days per week, learning theories of relevant courses under the tutelage of school lecturers; in enterprises, professionals with practical experience lead apprentice students to work on site, mainly apply their classroom learning, for at least 3 days a week. Through this dual training mode, students can achieve theoretical education in the classroom and practical experience at work. Thus, the purpose of learning for practical use is achieved, which improves the learners' future career prospects (Thomas 1997). Ultimately, this project can considerably bridge the gap between theory and practice, in turn mitigating the talent mismatch crisis.

In 2009, Taiwan established a plan and upgraded it in accordance with the domestic situation, which is referred to as the dual system of vocational training policy (DSVTP) program. Under the new institutional arrangement, students are provided with discounts for tuition payment along with stipends from enterprises to reduce their financial burden. With the operational cost shared by governments, schools, and enterprises, Taiwan's DSVTP is similar to Switzerland's dual system (Hanhart \& Bossio 1998). Students who pass the required exam and complete the training program are awarded an official certificate issued jointly by the Ministry of Education, Ministry of Labor (formerly referred to as the Council of Labor Affairs), and the concerned enterprise (DSVTP official Website 2015). Taiwan's current DSVTP is sponsored by the Ministry of Labor in collaboration with the Ministry of Education and is co-organized by the five local divisions of the Ministry of Labor. The DSVTP, with a ratio of vocational education to internship training time of approximately 3:7, was established to primarily implement job rotation and offer related training to help enterprises cultivate the required manpower.

Considering the aforementioned arguments and examples, this study conducted a survey on young students participating in the DSVTP to understand their satisfaction with the project and whether such satisfaction affects their willingness to continue working at their current job in the future; an additional objective of the research was to determine whether the DSVTP can ultimately achieve the goal of matching educational qualification with career requirements. In other words, from the perspective of policy analysis, this study allows us to evaluate overall satisfaction level of Taiwan's DSVTP program and further, its potential effect in retaining participating students at current intern job, so as to reduce youth unemployment. Furthermore, in terms of research methodology, structural equation modeling (SEM) was employed because it enables latent variables to be measured according to multiple observed indicators and can accommodate multiple dependent variables simultaneously. These advantages, which are considerably limited in traditional regression analysis, are useful for the current study's sophisticated analytical framework. Through SEM and the established theoretical framework, the study addressed its research questions. Additionally, policy suggestions were summarized on the basis of students' feedback.

The research questions examined in this study are outlined as follows:

1. What are the satisfaction levels of students participating in the DSVTP program for school study, enterprise internship, and self-involvement? 
2. Does students' overall satisfaction with the DSVTP program influence their intentions to stay at their current internships or related jobs?

\section{Literature review}

Education mismatch, particularly concerning the employment of young people, engenders considerable problems (Kim \& Park 2016; Korpi \& Tahlin 2009; Nordin et al. 2010; Zhu 2014); therefore, governments worldwide have been endeavoring to address such problems. Currently, numerous solutions have been raised to address the problems. One method highly recommended by experts is the adoption of the dual education system. We review the literature relevant to our theoretical framework as follows.

\section{Studying and internship satisfaction}

A widely recognized set of measurement and testing theories have gradually been developed for research on satisfaction. Preliminary research on satisfaction has been conducted on customer satisfaction behavior in the fields of business administration and marketing science. The scope of such research has subsequently been extended to include civilians' satisfaction with the performance of government departments or public servants. Initially, such research was based on expectancy disconfirmation theory (Anderson and Sullivan 1993; Kim et al. 2007; Oliver 1980; Oliver \& DeSarbo 1988) and then extended to the direct measurement of service quality, as advocated by Cronin and Taylor (1992), who argued that consumers' perception of service quality should be based on the evaluation of service satisfaction. In Taiwan, academic research has commonly applied questionnaires to measure individuals' subjective satisfaction.

Several researchers have advocated the implementation of internship programs at schools. Zopiatis (2007:66) argued that there are "significant benefits that internships provide both to the hospitality properties that employ student interns and the educational institutions that are involved in such practices". Internships also allow students to acquire valuable work experience and explore career paths simultaneously. Considering these benefits of internship programs, increasing numbers of studies have investigated the satisfaction levels of students participating in internship programs in Taiwan (Chen and Chen 2011; Ko 2008; Lee 2014). Although the satisfaction of students participating in such programs is crucial for the concerned government authorities, increasing youth employment to reduce talent mismatches or youth unemployment rates must be the ultimate policy goal. Hence, studying students' intentions to leave or stay at their current internships is particularly essential in Taiwan (Lee and Chao 2013). Most studies in Taiwan have demonstrated that demographic background is associated with internship satisfaction; nevertheless, such studies have primarily focused on the hospitality industry in Taiwan. Hence, in addition to demographic background, students' subjective expectation plays a major role in their satisfaction with their internship programs. This argument is supported by the findings of previous research. For example, Beggs et al. (2008) suggested that discrepancies usually exist between students and practitioners with respect to the expected role, skills, and responsibilities of interns, which can eventually affect participants' satisfaction levels. 


\section{Self-involvement}

In general, employees' SI in the workplace is simply a part of their job involvement. However, students' SI in schools is associated with learning engagement. For students participating in the DSVTP, SI may be categorized into both job involvement and learning involvement. Accordingly, we present a review of the literature on both categories.

Rahati et al. (2015:33) defined job involvement "as internalizing the value of goodness and the importance of working among people. It is a subjective condition that makes people devoted to their work". Additionally, Schaufeli et al. (2002:73) argued that "engaged employees have a sense of energetic and effective connection with their work activities, and they see themselves as able to deal completely with the demands of their job". Because the positive mindset engendered by job involvement may promote work performance, psychologists are also committed to measuring job involvement sentiment. Lodahl and Kejner (1965) pioneered the operational definition of job involvement. Kanungo (1982) subsequently developed the most comprehensive and consistent measurement tool for job involvement on the basis of the definition provided by Kejner. Several researchers have regarded job involvement as the driving force behind organizational commitment or performance. For example, Rahati et al. (2015) conducted a correlation analysis between job involvement and organizational commitment. Kaplan et al. (1991) argued that the relationship between job involvement and job satisfaction is a critical research topic. Consequently, on the basis of previous studies, we assumed that the degree of SI would be associated with satisfaction with the DSVTP, which would subsequently influence willingness to stay at a job.

Appleton et al. (2008) conducted a comprehensive review of learning involvement, stating that learning involvement comprises students, schools, academic activities, and other constructs; specifically, students' learning involvement should also include participation in school activities (e.g., community activities and work education). Nevertheless, students participating in the DSVTP program are different from general students, and their participation in general school activities may not be important in this study. Hence, we focused on academic activities with regard to learning involvement; specifically, we assessed the actual learning involvement of the students interviewed.

\section{Influence of internship programs on students' career choices}

March and Simon (1993:84) explained organizational equilibrium as "a statement of the conditions under which an organization can induce its members to continue their participation and, hence, assure organizational survival". With adequate inducements, an organization can stimulate its members to cultivate mentalities that match the organization's goals, thus encouraging them to work toward actualizing such goals. In other words, when a balance is achieved between contributions and inducements, the resulting equilibrium status allows the organization to thrive. If the inducement is greater than the contribution, then the members' turnover rate is lower (and vice versa). Furthermore, Dawis and Lofquist (1984) proposed the theory of work adjustment, stating that successful job adaptation is based on the compatibility between an employee's work personality and work environment. Hence, incompatibility between employees' personal traits and their work environment will easily result in poor job adaptation. 
Chen and Shen (2011) focused on the effect of the satisfaction with off-campus internships on their intentions to continue in the hospitality industry. They considered students in higher technical and vocational schools and indicated that students' satisfaction with schools and enterprises as well as their self-satisfaction would positively affect their overall satisfaction with the internships, which would in turn influence their intentions to stay in the hospitality industry.

Generally, most studies have examined empirical outcomes in the hospitality industry and confirmed that internship satisfaction (or job satisfaction) encourages employees to continue working in the same or related industry. Nevertheless, Zopiatis (2007) posited a different stance, stating that internship projects in the hospitality industry may cause persistent troubles and affect the interns' willingness to stay in the industry.

Ko and Sidhu (2012) conducted a case study by recruiting university students in Singapore in order to explore the effect of internship satisfaction on students' career choices in public organizations. They concluded that students with unsatisfactory internship experiences are less likely to work in public organizations than those without any internship experience. Similar to the findings of Chen and Chen (2011), Ko and Sidhu asserted that internship experience can significantly influence students' career choice.

In summary, current research on students' satisfaction with internship programs has focused on only specific industries. To bridge this research gap in the literature, we focused on students participating in the dual educational program in Taiwan, irrespective of their industry background.

\section{Research method and hypotheses}

We developed an empirical model and formulated research hypotheses on the basis of the model.

\section{Research method}

In this research, we attempted to analyze how DSVTP program participants' satisfaction with their education institutions and with the companies where they executed their internships affects their intentions to leave or stay at their current jobs. Therefore, we established an empirical model to adequately illustrate the multifaceted dimensions considered in our quantitative analysis (Fig. 2) by using SEM.

We conducted a pretest to determine the reliability and validity of our survey instrument. ${ }^{3}$ Notably, we addressed the potential problem of common method variance (CMV), which commonly affects survey results. Specifically, a survey questionnaire was constructed using measurement scales from previous studies. Using the approach of stratified random sampling, we surveyed 926 participants of the DSVTP program across Taiwan in two waves to mitigate $\mathrm{CMV}^{4}$ After excluding samples with missing values (which is a strict requirement under SEM analysis), we analyzed valid samples from

\footnotetext{
${ }^{3}$ We distributed 140 pretest questionnaires among DSVTP program participants, of which we collected 90 valid samples. Subsequently, we conducted relevant pretest analysis to ensure that our survey questions properly captured the content of each factor.

${ }^{4}$ In the first wave of the survey, the questionnaire containing factors of SLS, EIS, and SI was distributed; 2 weeks later, the second wave of the survey was conducted, in which the questionnaire containing factors of GS and ISCJ was distributed to the same survey respondents. The survey period was approximately between December 20, 2016, and January 6 , 2017.
} 


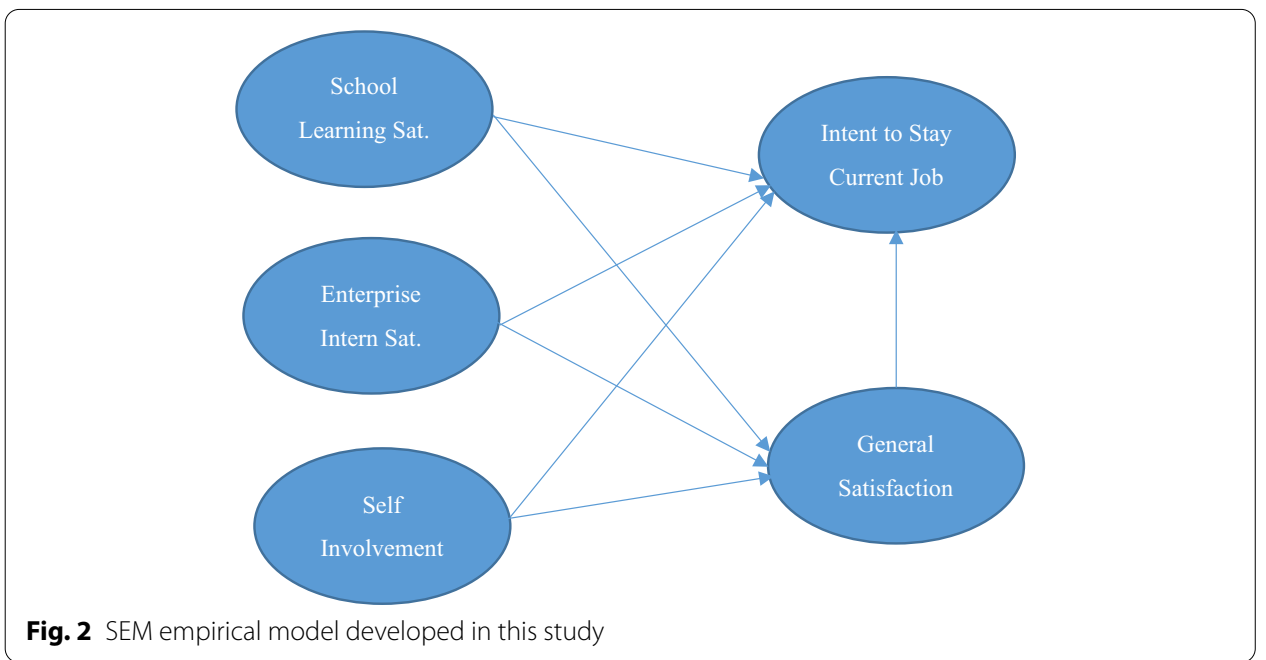

722 respondents with Amos 24 version. Most of the data were derived from respondents' responses to survey questions inquiring their attitude toward the DSVTP program; responses were provided on a 4-point Likert scale.

\section{Research hypotheses}

According to our research framework and literature review, we proposed the following hypotheses and explored them through our empirical model:

H1 School learning satisfaction is positively associated with DSVTP general satisfaction.

H2 Enterprise internship satisfaction is positively associated with DSVTP general satisfaction.

H3 Self involvement is positively associated with DSVTP general satisfaction. ${ }^{5}$

H4 DSVTP general satisfaction is positively associated with intention to stay in the current job.

H5 School learning satisfaction is positively associated with intention to stay in the current job.

H6 Enterprise internship satisfaction is positively associated with intention to stay in the current job.

H7 Self involvement is positively associated with intention to stay in the current job.

\footnotetext{
${ }_{5}^{5}$ The Self Involvement factor was further divided into job involvement (JI) and learning involvement (LI) sub-factors due to the diversified nature of the DSVTP program.
} 
Table 1 Descriptive statistics of respondents

\begin{tabular}{|c|c|c|}
\hline Variable name & Variable content & Numbers (\%) \\
\hline \multirow[t]{2}{*}{ Gender } & Male & $505(70.04 \%)$ \\
\hline & Female & $216(29.96 \%)$ \\
\hline \multirow[t]{5}{*}{ Region ${ }^{\S}$} & Northeast & $162(22.4 \%)$ \\
\hline & North & $65(9 \%)$ \\
\hline & Central & $190(26.3 \%)$ \\
\hline & Southwest & $192(26.6 \%)$ \\
\hline & South & $113(15.7 \%)$ \\
\hline \multirow[t]{3}{*}{ Age } & Under 18 & $93(12.9 \%)$ \\
\hline & $19-22$ years old & $597(82.9 \%)$ \\
\hline & Over the age of 23 & $30(4.2 \%)$ \\
\hline \multirow[t]{2}{*}{ Industry } & Service sector & $371(51.4 \%)$ \\
\hline & Non-service sector & $351(48.6 \%)$ \\
\hline \multirow[t]{6}{*}{ Annual family income } & Below $\$ 400,000(\$ 14,285)^{\#}$ & $219(32.4 \%)$ \\
\hline & $\$ 410,000-\$ 550,000(14,642-19,643)$ & $118(17.5 \%)$ \\
\hline & $\$ 560,000-\$ 700,000(\$ 20,000-26,786)$ & $89(13.2 \%)$ \\
\hline & $\$ 710,000-\$ 850,000(\$ 25,357-30,357)$ & $87(12.9 \%)$ \\
\hline & $\$ 860,000-\$ 1,000,000(\$ 30,714-35,714)$ & $85(12.6 \%)$ \\
\hline & Above $\$ 1,010,000(\$ 36,071)$ & $77(11.4 \%)$ \\
\hline \multirow[t]{5}{*}{ Average monthly salary } & Less than $\$ 10,000(\$ 357)$ & $22(3.1 \%)$ \\
\hline & $\$ 10,001-\$ 15,000(\$ 357-536)$ & $206(28.8 \%)$ \\
\hline & $\$ 15,001-\$ 20,000(\$ 536-714)$ & $324(45.3 \%)$ \\
\hline & $\$ 20,001-\$ 25,000(\$ 714-893)$ & $145(20.3 \%)$ \\
\hline & More than $\$ 25,001(\$ 893)$ & $18(2.5 \%)$ \\
\hline
\end{tabular}

${ }^{\S}$ Regions are categorized on the basis of the distribution of official agencies' branch office

\# Numbers in parentheses are in US dollar which is calculated at the exchange rate of USD : NTD $=1: 28$

\section{Results and discussion}

This section presents the results of the empirical analysis, which comprise the descriptive statistical results of sample observations, SEM measurement model, and SEM structural model.

\section{Descriptive statistical analysis}

We analyzed 722 valid responses in this study. We initially collected data pertaining to the participants' demographic background, which are presented in Table 1.

The ratio of male to female students participating in the DSVTP program was nearly 7:3 (Table 1). The geographical distribution of the respondents was in accordance with the general population distribution. Approximately half of the respondents were determined to be in the service industry, and the other half were determined to be in nonservice industries. Moreover, most of the respondents, roughly $60 \%$, came from families with an annual income of less than NT\$700,000. Most of the respondents earned less than NT $\$ 20,000$ a month. This result is consistent with the general public's perception that the majority of students participating in the DSVTP program are from low- and middle-income families. To further explore the satisfaction level for diversified demographic background, we conduct ANOVA analysis on annual family income and average monthly salary. While there is no statistical significance 
Table 2 Analysis of variance on average monthly salary

\begin{tabular}{|c|c|c|c|}
\hline Factor & Average monthly salary & F value & Variance source \\
\hline & Less than $\$ 10,000: 2.84$ & & \\
\hline School & $\$ 10,001-\$ 15,000: 3.01$ & & \\
\hline Learning & $\$ 15,001-\$ 20,000: 2.95$ & 1.875 & \\
\hline \multirow[t]{3}{*}{ Satisfaction } & $\$ 20,001-\$ 25,000: 2.89$ & & \\
\hline & More than $\$ 25,001: 3.03$ & & \\
\hline & Less than $\$ 10,000: 2.57$ & & \\
\hline Enterprise & $\$ 10,001-\$ 15,000: 2.77$ & & More than $\$ 25,001>$ \\
\hline Internship & $\$ 15,001-\$ 20,000: 2.66$ & $5.243^{* * *}$ & $\$ 15,001-\$ 20,000$ \\
\hline \multirow[t]{3}{*}{ Satisfaction } & $\$ 20,001-\$ 25,000: 2.85$ & & $\$ 20,001-\$ 25,000>$ \\
\hline & More than $\$ 25,001: 3.11$ & & $\$ 15,001-\$ 20,000$ \\
\hline & Less than \$10,000: 2.87 & & \\
\hline Self & $\$ 10,001-\$ 15,000: 3.01$ & & \\
\hline \multirow[t]{4}{*}{ Involvement } & $\$ 15,001-\$ 20,000: 2.95$ & 1.205 & \\
\hline & $\$ 20,001-\$ 25,000: 2.94$ & & \\
\hline & More than $\$ 25,001: 3.05$ & & \\
\hline & Less than $\$ 10,000: 2.59$ & & \\
\hline General & $\$ 10,001-\$ 15,000: 2.81$ & & \\
\hline \multirow[t]{4}{*}{ Satisfaction } & $\$ 15,001-\$ 20,000: 2.79$ & $2.097^{*}$ & \\
\hline & $\$ 20,001-\$ 25,000: 2.84$ & & \\
\hline & More than $\$ 25,001: 3.03$ & & \\
\hline & Less than $\$ 10,000: 2.25$ & & More than $\$ 25,001>$ \\
\hline Intent to & $\$ 10,001-\$ 15,000: 2.32$ & & Less than $\$ 10,000$ \\
\hline Stay & $\$ 15,001-\$ 20,000: 2.43$ & $6.324^{* * *}$ & More than $\$ 25,001>$ \\
\hline \multirow[t]{2}{*}{ Current Job } & $\$ 20,001-\$ 25,000: 2.59$ & & $\$ 10,001-\$ 15,000$ \\
\hline & More than $\$ 25,001: 2.90$ & & $\begin{array}{l}\$ 20,001-\$ 25,000> \\
\$ 10,001-\$ 15,000\end{array}$ \\
\hline
\end{tabular}

on annual family income for each satisfaction level, there is statistical significance for average monthly salary as Table 2 exhibit.

Our ANOVA analysis reveals that average monthly salary is significantly associated with enterprise internship satisfaction and their intention to stay at the current job. That is, DSVTP participants with high monthly salary tend to exhibit higher satisfaction level on enterprise internship program and are more likely to stay at intern or current job, as opposed to low monthly salary earners. More causal relationship between factors will be explored in the later page of SEM analysis.

Respondents' satisfaction with the DSVTP program are detailed in Appendix. We observed that the respondents demonstrated high score in SI and SLS and low score in GS and EIS. The respondents' scores were lowest for ISCJ, suggesting that students participating in the DSVTP program are less likely to stay at their current jobs after graduating from this program. However, considering the correlations between the various dimensions, we noted that the aforementioned findings were generally in line with our research hypotheses. 


\section{Measurement model: confirmatory factor analysis}

Confirmatory factor analysis (CFA) is a critical component of SEM. Thompson (2004) suggested that researchers should analyze a measurement model before performing structural model analysis because the measurement model can correctly reflect the research dimensions. Accordingly, we performed composite reliability (CR) and average variance extracted (AVE) assessments. The internal consistency of the indicators, as recommended by Fornell and Larcker (1981), a CR value of 0.6 or higher represents good internal consistency. Moreover, a higher AVE indicates higher reliability and convergence validity of latent variables; the AVE must be greater than 0.5 to ensure favorable reliability and validity. The CR values were between 0.813 and 0.877 , and the AVE values were between 0.540 and 0.706 . We used AMOS 21 software to conduct model analyses.

The empirical results obtained for each dimension are presented in Table 3. Although favorable CFA results were obtained for most factors, no goodness-of-fit statistics were derived for GS and ISCJ; this is because these factors constituted the so-called saturated model factors. The reliability values obtained for all other dimensions met the necessary criteria in terms of CR, AVE, and fit indices.

In addition to using CFA to verify the reliability and convergence validity of our empirical model, we used analyzed discriminant validity to confirm that the items in each dimension did not exhibit high correlations. Accordingly, we applied the bootstrap method under the consideration that the null hypothesis would be rejected if the calculated upper and lower limits did not contain 1, which would demonstrate the existence of discriminant validity between two dimensions (Torkzadeh et al. 2003; Liu 2013). Table 4 presents the discriminant validity analysis results.

Finally, to further confirm the stability of our empirical model, we conducted multigroup analysis to test the cross-sample validity of our empirical model. In this analysis, we randomly and equally divided the collected samples into two groups and then tested whether significant differences existed between the two groups in order to evaluate the model's stability. Table 5 lists the analysis results.

Among the five indicators used in the cross-validity analysis, the P values obtained for the first four indicators showed no significant difference between the two groups. Additionally, the $\triangle$ CFI values were ideally less than 0.01 (Cheung \& Rensvold 2002), and the $\triangle T L I$ values were less than 0.05 (Little 1997). Specifically, the analysis results of the two randomly assigned groups were consistent, demonstrating the sufficient validity and stability of our empirical model. ${ }^{6}$

\section{Structural model}

We present the results of the structural model's path coefficients for each factor and the general model's goodness-of-fit indices. We used SEM to develop our empirical model in

\footnotetext{
${ }^{6}$ Although the measurement measured residuals, the fifth index in the cross-validity analysis table showed that the $\mathrm{P}$ value was extremely small. Byrne (2010) considered the standard of measurement residuals to be too strict; thus, even if the P value was extremely small, the cross-validity of the model was not impaired.
} 


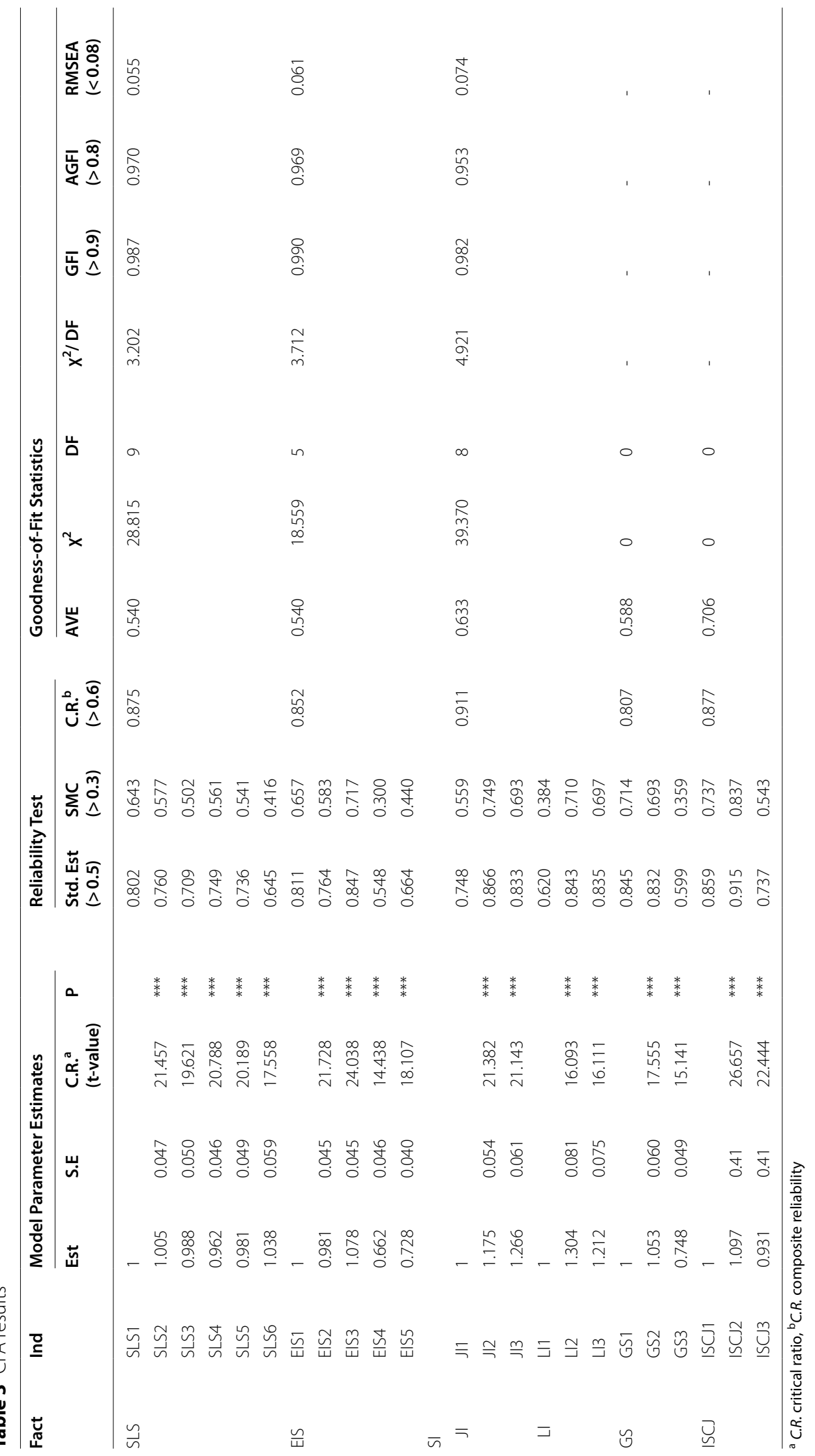


Table 4 CFA results: discriminant validity

\begin{tabular}{|c|c|c|c|c|c|c|c|}
\hline \multicolumn{2}{|c|}{$\begin{array}{l}\text { Factor } \\
\text { correlation }\end{array}$} & \multicolumn{2}{|l|}{$\psi \pm 1.96 \sigma$} & \multicolumn{2}{|c|}{$\begin{array}{l}\text { Bias-corrected } \\
\text { Percentile Method }\end{array}$} & \multicolumn{2}{|c|}{ Percentile method } \\
\hline & & Lower limit & Upper limit & Lower limit & Upper limit & Lower limit & Upper limit \\
\hline $\mathrm{SLS} \leftrightarrow$ & EIS & 0.382 & 0.566 & 0.383 & 0.563 & 0.380 & 0.561 \\
\hline $\mathrm{SLS} \leftrightarrow$ & 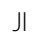 & 0.323 & 0.515 & 0.322 & 0.515 & 0.320 & 0.514 \\
\hline $\mathrm{SLS} \leftrightarrow$ & $\mathrm{LI}$ & 0.372 & 0.564 & 0.366 & 0.554 & 0.370 & 0.556 \\
\hline $\mathrm{EIS} \leftrightarrow$ & 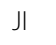 & 0.710 & 0.822 & 0.709 & 0.817 & 0.710 & 0.817 \\
\hline $\mathrm{EIS} \leftrightarrow$ & $\mathrm{LI}$ & 0.197 & 0.369 & 0.197 & 0.367 & 0.199 & 0.367 \\
\hline$J \leftrightarrow$ & $\mathrm{LI}$ & 0.274 & 0.462 & 0.268 & 0.452 & 0.270 & 0.456 \\
\hline
\end{tabular}

Bootstrap samples $=1000$

Table 5 CFA results: Cross-validity

\begin{tabular}{|c|c|c|c|c|c|}
\hline & Variance & Chi square & P value & $\begin{array}{l}\Delta C F I \\
(\leqq 0.01)\end{array}$ & $\begin{array}{l}\Delta \mathrm{TLI} \\
(\leqq 0.05)\end{array}$ \\
\hline Meas. variable weights & 17 & 14.703 & 0.617 & 0.001 & -0.002 \\
\hline Structural weights & 26 & 25.865 & 0.471 & -0.001 & -0.003 \\
\hline Structural covariance & 36 & 40.283 & 0.286 & 0.000 & -0.003 \\
\hline Structural residuals & 38 & 40.529 & 0.359 & 0.000 & -0.004 \\
\hline Measurement residuals & 61 & 94.473 & 0.004 & -0.003 & -0.002 \\
\hline
\end{tabular}

$H_{0}$ Model1 = Model2; CFI Comparative Fit Index, TLITucker-Lewis Index

order to analyze the effects of SLS, EIS, JI, LI, GS, and ISCJ (Fig. 3). The path coefficients obtained for the factors are presented in Table 6. Our empirical results revealed that the coefficients for most paths were statistically significant, except that for the path from LI to ISCJ. Additionally, most of the empirical results were consistent with our research hypotheses, except for a few results, which are discussed in the Sect. 6 of this paper.

We also noted favorable goodness-of-fit indices for our empirical model. ${ }^{7}$ Table 6 shows the desirable ranges of all fit indices along with the indices obtained for our structural model from the actual SEM calculation. Our model's fit indices are shown to perfectly match the desirable ranges (Table 7).

Concerning the overall empirical model, we noted that EIS, job involvement, and DSVTP GS were positively correlated with ISCJ, which are consistent with the results of previous studies that EIS, job involvement, and Dual System Project satisfaction were all positively correlated with willingness to stay in the current job. SLS had a significant negative correlation with willingness to stay in the current job in the future. The possible explanation for this finding is that the students participating in the DSVTP program who were actively involved in their learning had relatively high expectations from their internship or high learning goals. Higher learning involvement could indicate lower satisfaction with the DSVTP. By contrast, students with passive learning involvement were unwilling to increase their efforts. Moreover, most of such students came from middle

\footnotetext{
${ }^{7}$ In this model, the only unsatisfactory indicator was the $x^{2}$ value, which was 458.331 . Kenny (2015) argued that the chisquare value is affected by the size of the sample number. If the number of samples is between 75 and 200 , the chi-square value of a model developed through SEM will usually meet the model fit requirement (i.e., the chi-square value is small and not statistically significant). However, if the number of samples exceeds 400, the chi-square value will usually be very large (i.e., it will be statistically significant). The number of samples in this study exceeded 700, resulting in a significant statistical result, meaning that the chi-square value was too large and that the P value approached zero.
} 


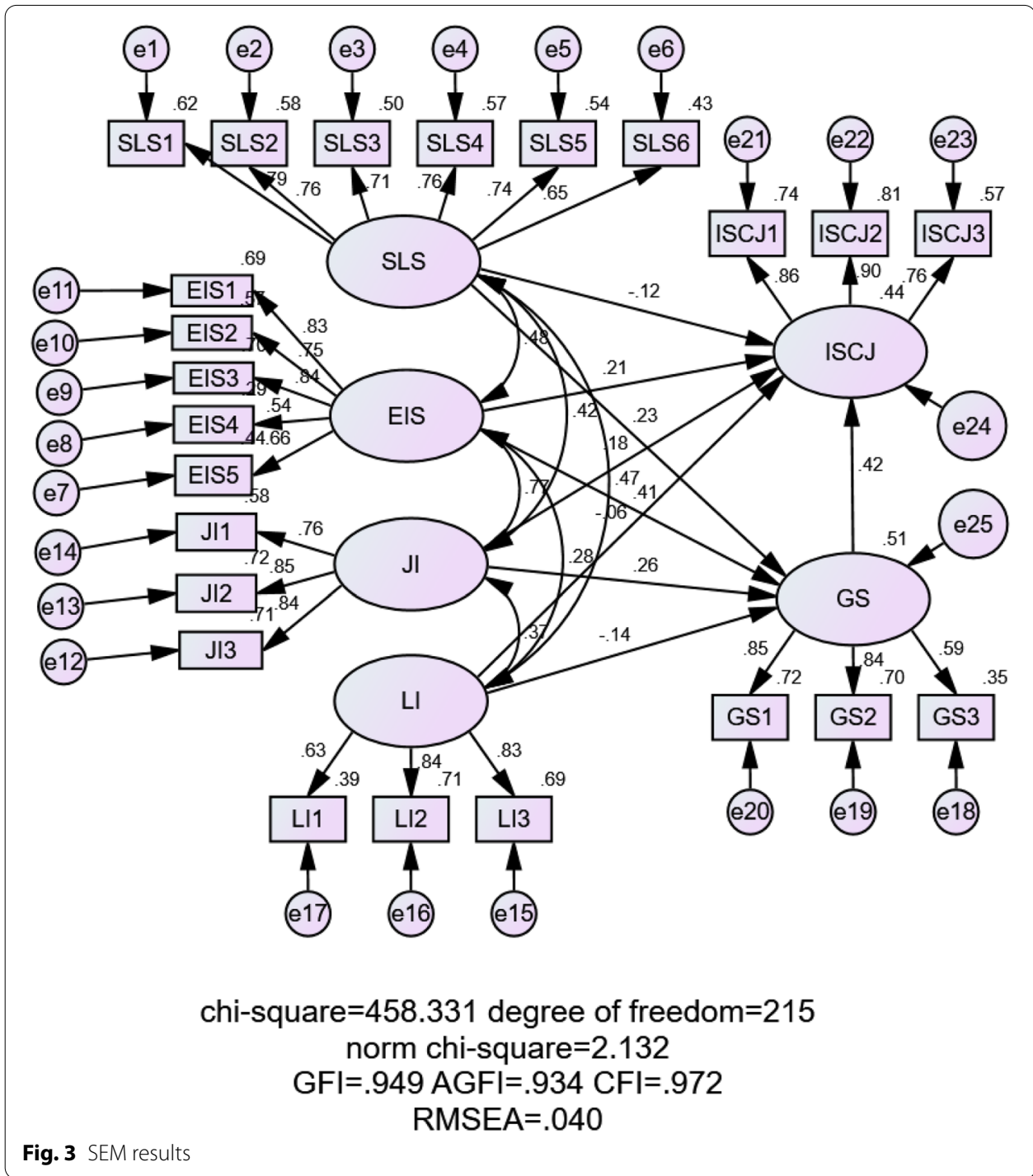

Table 6 Path coefficients obtained for factors

\begin{tabular}{lcc}
\hline Factors & Path coefficients & P-value \\
\hline $\mathrm{SLS} \rightarrow \mathrm{GS}$ & 0.23 & $* * *$ \\
$\mathrm{EIS} \rightarrow \mathrm{GS}$ & 0.41 & $* * *$ \\
$\mathrm{~J} \rightarrow \mathrm{GS}$ & 0.26 & $* * *$ \\
$\mathrm{LI} \rightarrow \mathrm{GS}$ & -0.14 & $* * *$ \\
$\mathrm{SLS} \rightarrow \mid S C J$ & -0.12 & $* *$ \\
$\mathrm{EIS} \rightarrow \mid S C J$ & 0.21 & $* *$ \\
$\mathrm{~J} \rightarrow \mid S C J$ & 0.18 & $* *$ \\
$\mathrm{LI} \rightarrow \mid S C J$ & -0.06 & \\
GS $\rightarrow$ ISCJ & 0.42 & $* * *$ \\
\hline
\end{tabular}

***P $<0.001 ; * * P<0.01$ 
Table 7 Recommended model goodness-of-fit indices and indices obtained from SEM

\begin{tabular}{llr}
\hline Model fit & Criteria value & SEM analysis value \\
\hline Absolute fit index & & \\
$X^{2}$ & The smaller the better & 458.331 \\
$X^{2} / \mathrm{d} f$ & $<3$ & 2.132 \\
GFI & $>0.900$ & 0.949 \\
$\mathrm{AGFI}$ & $>0.900$ & 0.934 \\
RMR & The smaller the better & 0.015 \\
RMSEA & $<0.080$ & 0.040 \\
Value-added fit index & & \\
NFI & $>0.900$ & 0.948 \\
CFI & $>0.950$ & 0.971 \\
RFI & $>0.900$ & 0.939 \\
IFI & $>0.900$ & 0.972 \\
TLI & $>0.900$ & 0.966 \\
Parsimony fit index & & \\
PNFI & $>0.500$ & 0.806 \\
PGFI & $>0.500$ & 0.739 \\
\hline
\end{tabular}

and lower class family backgrounds; thus, they paid more attention to the monetary rewards, which also affected their overall satisfaction with the DSVTP.

\section{Model specification: CMV test}

To further validate our empirical model, we evaluated CMV. Single-factor CFA test has commonly been used by researchers to assess CMV (McFarlin and Sweeney 1992). This test is a post hoc procedure that is often used to determine whether the variance in data can be largely attributed to a single factor. The remedies for CMV involve ex ante research design and ex post statistical analysis (Chang et al. 2010); in this study, we adopted both remedies. Because we conducted our survey at two different time points by using independent variables and dependent variables, we further employed Harman's single-factor test as the ex post statistical analysis method.

Single-factor CFA test is quite simple and straightforward. The test involves comparing a single-factor model with multifactor model and is based on the null hypothesis that the two models are no different $\left(H_{0}\right.$ : single-factor model $=$ multifactor model). After calculating the chisquare value, we could determine whether the null hypothesis would be rejected or accepted.

Figure 4 displays the single-factor CFA model: $\chi^{2}(230, N=722)=3903.573$. Furthermore, Fig. 5 illustrates the multi-factor CFA model: $\chi^{2}(215, N=722)=458.331$. According to STATABLE software, we obtained the following statistics for the two models: $\triangle \mathrm{df}=230-215=15$; $\triangle \mathrm{x}^{2}=3903.573-458.331=3445.242$. In addition, the corresponding $\mathrm{P}$ values of the models were close to zero $(\fallingdotseq 0)$. These results suggest that the null hypothesis should be rejected. Consequently, the two models were determined to be different, indicating the lack of CMV in this study's dimensions. 


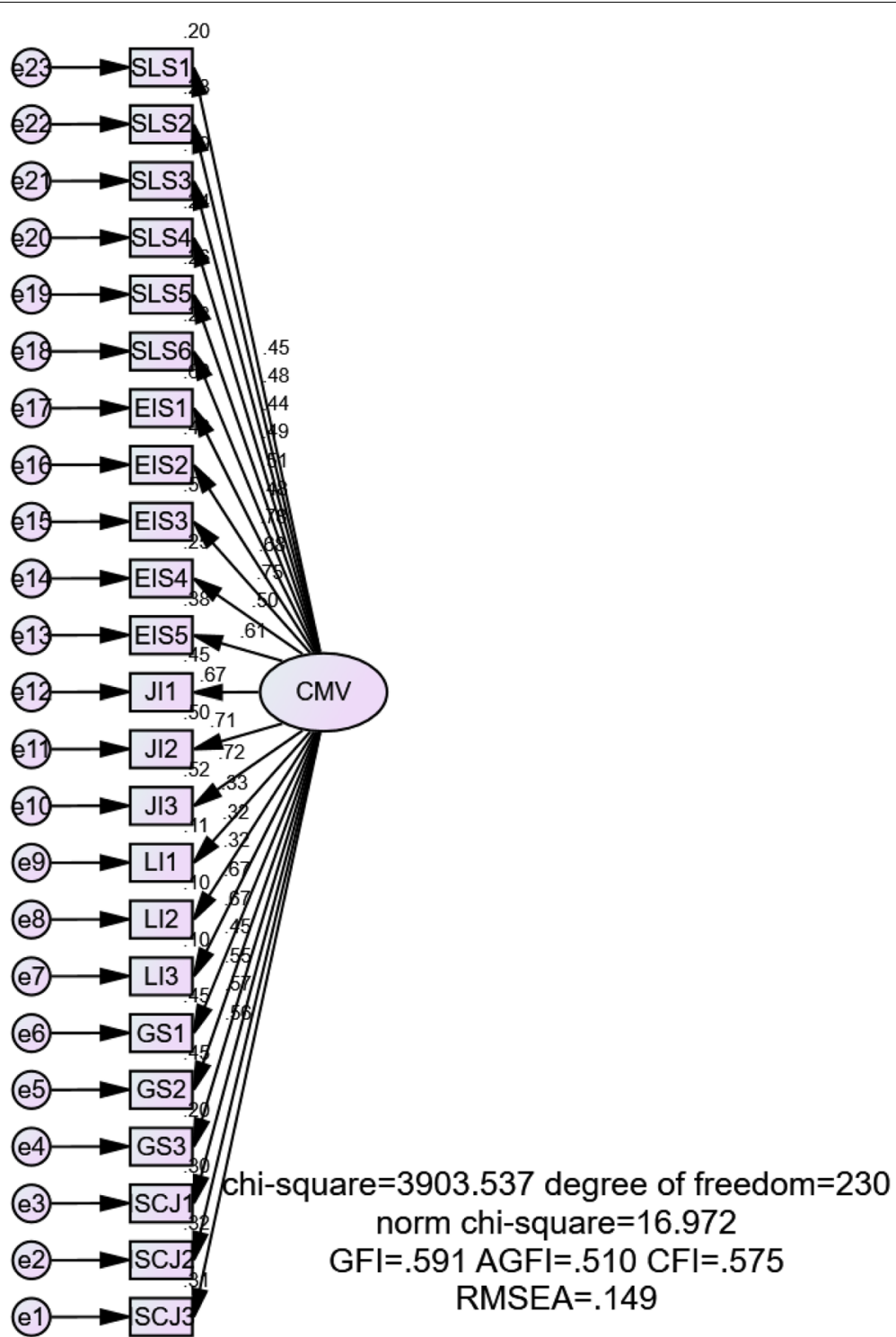

Fig. 4 Single-factor CFA model

\section{Conclusion}

We conducted a survey on students participating in the DSVTP program in Taiwan to determine their satisfaction with the program and corresponding intentions to stay in the companies or industry where they executed their internships. Approximately 926 questionnaires were distributed among more than 3000 participants through random sampling. After procuring 722 sample observations, we developed an empirical model through SEM to explore the correlation between factors and examine the model specification in order to validate the parameter estimation of SEM model. The overall parameters of our model were essentially in accordance with our research hypotheses, and the model specification tests produced desirable results, suggesting that our empirical analysis results may not be affected by CMV. Our 


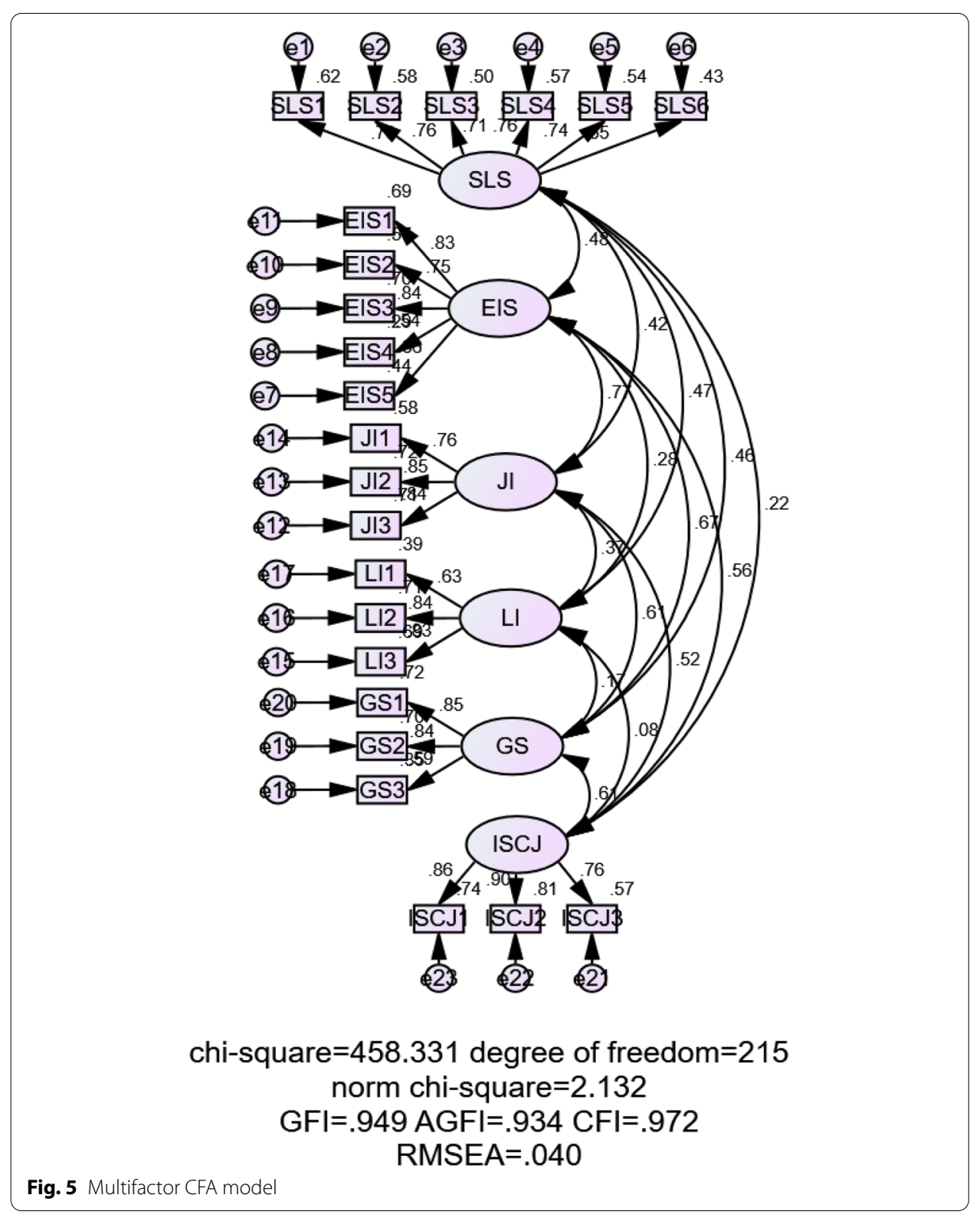

empirical model suggested that school learning satisfaction, enterprise internship satisfaction, and job involvement were significantly and positively correlated with the respondents' general satisfaction with the DSVTP program and that enterprise internship satisfaction, job involvement, and general satisfaction were positively correlated with the intentions to stay at the current job.

On the basis of the statistical analysis results, we present policy recommendations that could serve as a reference in future reforms of the dual education system in Taiwan. First, school learning satisfaction and learning involvement seemed to have no positive correlation with the respondents' intentions to stay at their current jobs. This phenomenon can be attributed to the so-called credentialism; that is, the belief (particularly dominant in Taiwan) that people tend to place higher value on general college education than vocational 
education. Accordingly, students with high learning involvement tend to pursue a higher education diploma rather than continue working at their vocational jobs. By contrast, students with high satisfaction with their enterprise internship and high job involvement tend to stay at their current vocational jobs after graduation. As a result, the training content should be diversified and adjusted to fit diverse studying contexts. For example, students should be allowed to switch to different enterprises while simultaneously learning different skills in order to expand their work experience and future career possibilities. This can ultimately foster youth employment among young people.

Second, our results reveal that $63.1 \%$ of the participants came from families with an annual household income of less than NT\$700,000 and that $77.2 \%$ of the participants earned a monthly salary of less than NT\$20,000. These figures indicate that participants of the DSVTP program are primarily from low- and middle-income backgrounds. Besides, along with our ANOVA analysis in Table 2, participants with high monthly salary tend to stay at the current intern job, as opposed to those with low monthly salary. Therefore, the government, as the facilitator of the DSVTP program, should advocate for the inclusion of the minimum monthly living allowance in the contract with participating enterprises. This policy measure can remarkably alleviate participants' financial burden and further encourage students to actively engage in the DSVTP program and enthusiastically prepare for the future job market.

Third, while our SEM analysis suggested that there is positive association between enterprise internship satisfaction and intent to stay at current job for DSVTP participants, the respondents seemed to have a relatively low satisfaction level with their enterprise internships. We thus suggest that relevant government agencies conduct informal visits to the enterprises participating in the DSVTP program. This policy measure would prevent participating enterprises from taking advantage of students and treating them as cheap labor. Well-established surveillance mechanisms can thus ensure the quality of the DSVTP program.

Finally, while we endeavored to develop a comprehensive and representative quantitative research design, our study has some limitations that should be addressed. We attempted to analyze sample observations through SEM, and we verified the results using several model tests to ensure that there were no errors in the model parameter estimations. Nevertheless, the cross-sectional nature of this study prevented us from studying, long-term variations of respondents' attitudes, which can be determined in longitudinal studies. Consequently, to ideally bridge this research gap, an annual survey should be conducted to investigate the time variations in DSVTP participants' attitudes. This can ensure that participants' satisfaction levels are readily captured and that government agencies initiate necessary policy measures for instant change. The measurement of "credentialism" can also be included in future survey design as the concept is widely believed in Taiwan's society. Alternatively, indepth qualitative interviews can be conducted to supplement the intrinsic deficiencies of a quantitative survey study. All of these measures can enable a proper policy evaluation of the DSVTP program and simultaneously provide guidance for future research endeavors.

\section{Appendix}

See Table 8. 
Table 8 Scores for each factor

\begin{tabular}{|c|c|c|c|c|}
\hline Factor & Sub-Factor & Item & Mean & Std \\
\hline \multirow[t]{7}{*}{ SLS } & \multirow[t]{7}{*}{ N.A } & The school offers diversified courses & 3.00 & 0.527 \\
\hline & & The school's curriculum will help me in my future & 2.94 & 0.558 \\
\hline & & After attending school courses, I have a flexible time schedule & 2.91 & 0.588 \\
\hline & & The teacher's teaching method is very good and suitable for my study & 2.98 & 0.542 \\
\hline & & The courses can improve my professional skills & 2.98 & 0.563 \\
\hline & & When I have problems in internship, the school can offer me help & 2.97 & 0.680 \\
\hline & & Average SLS Scores & 2.96 & 0.457 \\
\hline \multirow[t]{6}{*}{ EIS } & \multirow[t]{6}{*}{ N.A } & Job placement is in line with students' needs and expertise & 2.73 & 0.755 \\
\hline & & The company provides with job rotation & 2.70 & 0.786 \\
\hline & & On - the - job training is carried out in an organized manner & 2.72 & 0.780 \\
\hline & & The salary of internship is acceptable & 2.67 & 0.740 \\
\hline & & Safety protection measures in internship places are well-equipped & 2.95 & 0.671 \\
\hline & & Average EIS Scores & 2.77 & 0.590 \\
\hline \multirow[t]{8}{*}{ SI } & \multirow[t]{4}{*}{ ال } & I think the job can elevate my self-esteem & 2.94 & 0.678 \\
\hline & & I am very devoted to this job & 2.91 & 0.689 \\
\hline & & For me, work is fun & 2.79 & 0.771 \\
\hline & & Average JI Scores & 2.88 & 0.629 \\
\hline & \multirow[t]{4}{*}{ LI } & I express my opinions enthusiastically in class discussions & 2.77 & 0.665 \\
\hline & & I take notes seriously in my class & 2.93 & 0.638 \\
\hline & & I listen to class lectures attentively and carefully & 2.93 & 0.599 \\
\hline & & Average LI Scores & 2.88 & 0.537 \\
\hline \multirow[t]{4}{*}{ GS } & \multirow[t]{4}{*}{ N.A } & What is your overall attitude toward training courses in DSVTP program? & 2.85 & 0.602 \\
\hline & & $\begin{array}{l}\text { What is your overall attitude toward the quality of training in the DSVTP } \\
\text { program? }\end{array}$ & 2.73 & 0.644 \\
\hline & & $\begin{array}{l}\text { The DSVTP program can reduce the gap between school education and } \\
\text { workplace skills }\end{array}$ & 2.84 & 0.636 \\
\hline & & Average GS Scores & 2.81 & 0.520 \\
\hline \multirow[t]{4}{*}{ ISCJ } & \multirow[t]{4}{*}{ N.A } & I intend to work in related jobs after graduation & 2.57 & 0.737 \\
\hline & & $\begin{array}{l}\text { I intend to engage in similar work to my internship training after gradua- } \\
\text { tion }\end{array}$ & 2.53 & 0.759 \\
\hline & & It is a good choice to work in the current job after graduation & 2.46 & 0.800 \\
\hline & & Average ISCJ Scores & 2.51 & 0.683 \\
\hline
\end{tabular}

\section{Acknowledgements}

The author is very grateful to Mr. Wei-Kai Pan, the graduate student, who endeavored in survey distribution and data collection.

\section{Authors' contributions}

$L C L$ performed the empirical study and was the major contributor of in writing the manuscript. The author read and approved the final manuscript.

\section{Funding}

Not applicable.

Availability of data and materials

Data available upon request.

\section{Declarations}

\section{Competing interests}

The author declares no competing interest.

Received: 21 December 2020 Accepted: 2 July 2021

Published online: 18 July 2021 


\section{References}

Anderson E, Sullivan M (1993) The antecedents and consequences of customer-satisfaction for firms. Mark Sci 12(2):125-143

Appleton J, Christenson S, Furlong M (2008) Student engagement with school: critical conceptual and methodological issues of the construct. Psychol Sch 45(5):369-386

Beggs B, Ross C, Bryan G (2008) A comparison of student and practitioner perspectives of the travel and tourism internship. J Hosp Leis Sport Tour Educ 7(1):31-39

Byrne B (2010) Structural Equation Modeling with AMOS: Basic Concepts, Applications, and Programming, 2nd edn. Routledge, New York

Chang S-J, van Witteloostuijn A, Eden L (2010) From the editors: common method variance in international business research. $J$ Int Bus Stud 41(2):178-184

Chen C-T, Chen C-F (2011) The influence of internship experiences on the behavioral intentions of college students in Taiwan Asia Pac Educ Res 20(1):73-92

Chen Z-L, Shen C-C (2011) The influence of internship program on students' career choice: case from hospitality and tourism related department in higher vocational education. J Hosp Tour 8(1):21-38 (in Chinese)

Cheung G, Rensvold R (2002) Evaluating goodness-of-fit indexes for testing measurement invariance. Struct Equ Model 9(2):233-255

Cronin J, Taylor S (1992) Measuring service quality: a reexamination and extension. J Mark 56(3):55-68

Dawis R, Lofquist L (1984) A Psychological Theory of Work Adjustment: An Individual-Differences Model and Its Application. University of Minnesota, Minneapolis

DSVTP official website (2018) https://www.dual.nat.gov.tw/toAction.do, 2018/01/01

Eichhorst W (2014) Does Vocational Training Help Young People Find a (Good) Job? IZA World of Labor 112:1-10

Fornell C, Larcker D (1981) Evaluating structural equation models with unobservable variables and measurement error: algebra and statistics. J Mark Res 18(3):382-388

Forster-Heinzer S, Holtsch D, Rohr-Mentele S, Eberle F (2016) Do They Intend to Stay? An empirical study of commercial apprentices'motivation, satisfaction and intention to remain within the learned occupation. Emp Res Vocat Educ Train 8:16. https://doi.org/10.1186/s40461-016-0041-0

Hanhart S, Bossio S (1998) Costs and benefits of dual apprenticeship: lessons from the swiss system. Int Labor Rev 137(4):483-500

Hanushek E (2012) Dual Education: Europe's Secret Recipe? CESifo Forum, ISSN 2190-717X, ifo Institut - Leibniz-Institut für Wirtschaftsforschung an der Universität München. München 13(3):29-34

Ho H-F (2015) Matching University Graduates' Competences with Employers' Needs in Taiwan. Int Educ Stud 8(4):122-133

Jeong Y, Lee A, Cho J (2018) Educational Mismatches and Job resolution in South Korea, the USA, and Germany. Asian-Pac Econ Liter 32(2):95-108

Kanungo R (1982) Measurement of job and work involvement. J Appl Psychol 67(3):341-349

Kaplan R, Boshoff A, Kellerman A (1991) Job Involvement and job satisfaction of South African Nurses compared with other professions. Curationis 14(1):3-7

Kenny, David (2015) Measuring Model Fit. Available from: http://davidakenny.net/cm/fit.htm, 2017/06/25

Kim H-K, Park S-J (2016) Do Skill Mismatches Create a Wage Penalty? Alternative Estimates for Korea. Asian Econ J 30(3):295-316

Kim K-J, Jeong I-J, Park J-C, Park Y-J, Kim C-G, Kim T-H (2007) The impact of network service performance on customer satisfaction and loyalty: high-speed internet service case in Korea. Expert Syst Appl 33(3):822-831

Ko W-H (2008) Training, satisfaction with internship program, and confidence about future careers among hospitality students: a case study of universities in Taiwan. J Teach Travel Tour 7(4):1-15

Ko K, Sidhu DJK (2012) The impact of internship in public organizations on university students' perception and career choice. Int Rev Admin Sci 78(4):710-732

Korpi T, Tahlin M (2009) Educational mismatch, wages, and wage growth: overeducation in Sweden, 1974-2000. Labour Econ 16(2):183-193

Lee C-F (2014) The determinants of hospitality internship quality from the perspectives of three stakeholders: a case from Taiwan. J Hosp Tour Educ 26(2):75-86

Lee C-S, Chao C-W (2013) Intention to "Leave" or "Stay" - The Role of Internship Organization in the Improvement of Hospitality Students'Industry Employment Intentions. Asia Pac J Tourism Res 18(7):749-765

Little T (1997) Mean and covariance structures (MACS) analyses of cross-cultural data: practical and theoretical issues. Multivar Behav Res 32(1):53-76

Liu L-H (2013) What drives performance budgeting to perform? a survey examination in Taiwan. Public Admin Res 2(2):58-72

Lodahl T, Kejner M (1965) The definition and measurement of job involvement. J Appl Psychol 49(1):24-33

March J, Simon H (1993) Organization, 2ND edn. Blackwell Publishers, Cambridge

McFarlin D, Sweeney P (1992) Distributive and procedural justice as predictors of satisfaction with personal and organizational outcomes. Acad Manag J 35(3):626-637

Nordin M, Persson I, Rooth D-O (2010) Education-occupation mismatch: is there an income penalty? Econ Educ Rev 29(6):1047-1059

Oliver R (1980) A cognitive model of the antecedents and consequences of satisfaction decisions. J Mark Res 17(4):460-469

Oliver R, DeSarbo W (1988) Response determinants in satisfaction judgements. Journal of Consumer Research 14(4):495-507

Palmer, Robert (2017) Jobs and Skills Mismatch in the Informal Economy. https://www.lo.org/wcmsp5/groups/public/---ed_ emp/--ifp_skills/documents/publication/wcms_629018.pdf. Accessed 9 Sept 2018

Park K (2018) Vertical and horizontal mismatches and career mobility: evidence from female college graduates. Asian-Pac Econ Liter 32(2):109-125

Rahati A, Sotudeh-Arani H, Adib-Hajbaghery M, Rostami M (2015) Job involvement and organizational commitment of employees of prehospital emergency medical system. Nurs Midwif Stud 4(4):33-38

Schaufeli W, Salanova M, Gozales-Roma V, Bakker A (2002) The measurement of engagement and burnout: a two sample confirmatory factor analytic approach. J Happiness Stud 3(1):71-92

Thomas D (1997) The German Dual System—A Model for Europe? Educ Train 39(8/9):297-302 
Thompson B (2004) Exploratory and Confirmatory Factor Analysis: Understanding Concepts and Applications. Washington D.C.: American Psychological Association

Torkzadeh G, Koufteros X, Pflughoeft K (2003) Confirmatory analysis of computer self-efficacy. Struct Equ Modeling 10(2):263-275

Zhu R (2014) The impact of major-job mismatch on college graduates' early career earnings: evidence from China. Educ Econ 22(5):511-528

Zopiatis A (2007) Hospitality internships in cyprus: a genuine academic experience or a continuing frustration? Int J Contemp Hosp Manag 19(1):65-77

\section{Publisher's Note}

Springer Nature remains neutral with regard to jurisdictional claims in published maps and institutional affiliations.

Submit your manuscript to a SpringerOpen ${ }^{\circ}$ journal and benefit from:

- Convenient online submission

- Rigorous peer review

- Open access: articles freely available online

- High visibility within the field

Retaining the copyright to your article

Submit your next manuscript at $\boldsymbol{\Delta}$ springeropen.com 